\title{
Possibly "the Truth, the Whole Truth and Nothing But the Truth": Attempting to Define Creative Nonfiction
}

\section{Ross Griffin}

School of English, UCC

\begin{abstract}
"The world is so taken up with Novels and romances, that it will be hard for a private history to be taken for genuine, where the names and other circumstances of the person are concealed, and on this account we must be content to leave the reader to pass his own opinion upon the ensuing sheets, and take it just as he pleases." (Daniel Defoe, Moll Flanders, 1722)
\end{abstract}

\section{Introduction}

Locating such works as Frank McCourt's Angela's Ashes or Michael Herr's Dispatches in any bookshop or library often presents an unexpected challenge for the average reader. As a nonfictional account firmly embedded in the author's personal experiences, there is strong reason to think that such books would be included in the History section, comfortably situated amongst similarly factual texts of historical discourse. Curiously, however, they are often found sharing shelf space with deliberately fictional novels. This example of inconsistent categorisation is a concern for many readers of such narratives, highlighting the inherent difficulty in establishing the exact status of any written work. However, this issue is acutely relevant to the literary form embodied by texts such as Dispatches, one which combines a distinctly novelistic style of writing with the most meticulous reportage to present a genre known informally as the 'literature of reality' or creative nonfiction. There remains a distinct absence of literary theory relating to the genre. This issue remains unresolved and, thus, the primary goal of my project is to provide this genre with a body of theory comparable to that of all other literary genres.

\section{Creative, Nonfiction?}

Creative nonfiction came to prominence in the twentieth century as a by-product of the counterculture movement in the US, which emerged at least in part, due to the continuing American participation in Vietnam during the 1960s. The genre's aim is to re-produce a written account of actual people, historical events and places which is unchanged from the manner in which they occurred in reality. While this approach distinguishes it from 
traditional fiction, creative nonfiction's use of literary devices normally reserved for fiction, such as character dialogue or the presence of a godlike narrator, differentiates it from conventional history or newspaper reportage. Yet despite this on-going uncertainty as to its exact character, the literary form has emerged as one of contemporary culture's predominant literary genres. Even more intriguingly, it has come to dominate nonfictional bestseller lists in both America and Europe, despite there being no obvious difference in composition between the nonfictional narratives and those typically found on the fictional bestseller lists.

Critics of the genre have regularly described creative nonfiction as a hybrid genre which is constructed by the author from fact, but conveyed to the reader using fictional techniques. However, by presenting a text where the factual and fictional are fused into one, the question remains as to what exactly the genre is; should it be viewed as a referential text much like a standard history book, or should it be interpreted as a highly subjective narrative very much similar to a personal diary and journal?

\section{You weren't there man!! (So why the Vietnam War?)}

The research material which will be used to resolve this issue is a selection of war literature inspired by the Vietnam War. The choosing of the Vietnam War is deliberate. As one of the most widely televised wars in history, the conflict in Vietnam exemplified the absence of a stable and objective authorial voice in its narration as both pro- and anti-war commentators offered startlingly contradictory commentaries on its events. This contrast was exacerbated by an independent media which, for the first time in modern warfare, was allowed unrestricted access to the battle-field. Their presence resulted in an outpouring of texts and imagery projecting horrors of war previously unseen by the majority and the widespread dissemination of a version of events completely at odds with that being propagated as fact by the dominant political and cultural forces in America. Such divergence inspired a tangible dissent amongst the American people which was appropriated and amplified by the Counterculture movement. As a consequence, a substantial body of fictional and nonfictional literature was produced, directly inspired by the Vietnam War, which directly questioned the very validity of America's own history.

Obviously, not all works of creative nonfiction are founded on military endeavour, either by the conflict in Vietnam or any other form of armed struggle over the centuries. However, the selection of the war-writing genre as the tool whereby I intend to test my definition of creative nonfiction is a deliberate choice of mine. It is a literary form dominated by works of creative nonfiction which was written by soldiers and journalists with personal and verifiable experiences of conflict. In addition, the representation of these experiences in literature emphasises one of the primary difficulties of creative nonfiction; accurately representing experiences without succumbing to the impulse to fictionalise certain events. 
Nonfictional texts recounting recollections of conflict are often written with more than just commercial success in mind. They frequently represent the author's desire to both remember fallen comrades and to share the traumatic experiences of war with those who were not there. As a result, the presence of such emotionally-laden narratives in war writing challenge creative nonfiction's claim to present a detached and objective account of events, which in turn, provides a suitably similar genre of writing from which to form a definition of creative nonfiction. Yet the legitimacy of these nonfictional accounts is challenged when veteran-authors also incorporate the wartime experiences of these texts into other deliberately fictional novels depicting the conflict. Thus, based upon the same events and formed using similar literary techniques, these corresponding narratives replicate the hazy borders existing between accepted histories and fiction, and underscore the uncertainty inherent in the genre of creative nonfiction.

In the genre of creative nonfiction, particularly those derived from the experiences of war, the authenticity of the text is founded on the fact that the author bore actual personal witness to the people and events they document in their narratives. Introductions, prologues, dedications or other material such as biographical notes concerning the author's past, while located externally from the text, are known in literary theory as 'frames' and are capable of influencing the manner in which a reader interprets a text. In the case of creative nonfiction, these frames generally reinforce the sense of reality suggested by the narrative.

\section{The making of a genre}

My research has to consider the different bodies of thought in order to form a definition of creative nonfiction. Historiography, the study of how history is researched and presented, and autobiographical theory each highlight the many difficulties of reproducing reality on paper. Both raise the question of how valid such an account can be considering that it could quite possibly have left out as many significant events as it includes. Any attempt to construct a robust definition of creative nonfiction requires extreme clarity in each of these fields. The project's primary research material adds further theoretical concerns specific to Vietnam War literature and any proposed definition of creation nonfiction derived from texts generated by this conflict would be incomplete without addressing two other related issues, trauma studies and orientalism. Trauma study is the attempted literary representation of an extremely distressful mental or physical event. Studies on trauma have shown how the survivor of such incidents often experiences an inability to accurately recollect the exact details of these events. Given the horrific nature of armed conflict, this issue is a prominent one in war literature and has been shown to affect both perpetrators and victims of trauma. Yet, problematically, the depiction of trauma in creative nonfiction virtually mirrors its portrayal in fiction. Orientalism is a body of learning which 
originally founded on the sense of difference between European and non-European cultures, specifically but not limited to, those found in the continent of Asia. It inferred a lopsided relationship between the respective societies, allowing Europe to hold the more dominant and civilised position. In the modern era, this role has been appropriated by the United States. Thus, in their military engagement with Vietnam, an alien culture which the majority of Americans were unfamiliar with at the time, the appearance of narratives which merely reinforced Western societal stereotypes of the orient instead of faithfully representing wartime experience was a common one, in both works of creative nonfiction and fiction.

\section{Conclusion}

Thus, using a selected body of Vietnam War literature, the primary concern of this project is to construct a body of literary theory for creative nonfiction, a genre which aims to faithfully represent reality, yet which at the same time, offers an extremely personal and subjective view of events. Despite having come to prominence over fifty years ago, aside from the occasional wave of New Journalistic nostalgia, it is under-theorised and underdiscussed in comparison to many other literary genres.

Ross Griffin is a first year doctoral candidate under the supervision of Prof Graham Allen and Dr Alan Gibbs. He would like to acknowledge the invaluable support and insight each has brought to this study. 